\title{
Beate Wagner
}

Jugendliche Lebenswelten nach 1945 
Beate Wagner

\section{Jugendliche Lebenswelten nach 1945}

Sozialistische Jugendarbeit zwischen Selbstdeutung und Reeducation

Springer Fachmedien Wiesbaden GmbH 1995 
ISBN 978-3-663-10448-3 ISBN 978-3-663-10447-6 (eBook)

DOI 10.1007/978-3-663-10447-6

(C) 1995 by Springer Fachmedien Wiesbaden

Ursprünglich erschienen bei Leske + Budrich, Opladen 1995

Das Werk einschließlich aller seiner Teile ist urheberrechtlich geschützt. Jede Verwertung außerhalb der engen Grenzen des Urheberrechtsgesetzes ist ohne $\mathrm{Zu}$ stimmung des Verlages unzulässig und strafbar. Das gilt insbesondere für Vervielfältigungen, Übersetzungen, Mikroverfilmungen und die Einspeicherung und Verarbeitung in elektronischen Systemen. 


\section{Inhalt}

1. Zeitenwende - Jugend nach dem 2. Weltkrieg 15

1.1 Prägungen - Nachkriegsjugend als Generationsgestalt ............. 22

1.1.1 Lebensbedingungen - Leben in Schutt und Trümmern ......... 27

1.1.2 Momentaufnahmen - Jugendliche über sich selbst .............. 35

1.1.3 Hoffnungsträgerin-zeitgenössische Erwartungen an die Jugend ............................................................................ 45

1.1.4 Jugendnot - Jugend zwischen Kriminalität und Schutzbedürftigkeit

1.2 Forschungsobjekt - Nachkriegsjugend im Blick der

Wissenschaft ....................................................................... 59

1.2.1. "Skeptische Generation“ - eine soziologische Analyse ....... 61

1.2.2 Verlorene Jugend - pädagogische Betrachtungen ............... 66

1.2.3 Trauerarbeit - Überlegungen zur kollektiven Psyche .......... 70

1.2.4 Zahlenwerk - Anfänge der empirischen Jugendforschung ... 73

1.2.5 Verarbeitungsmuster - Ansätze zur Mentalitätsforschung ... 76

1.3 Folgen der Instrumentalisierung - Zusammenfassende

Betrachtungen über jugendliches Nachkriegsleben 80 


\section{Befreiung vom Faschismus - Erziehung zur Demokratie}

2.1 Rahmenbedingungen - Möglichkeiten von Jugendarbeit unter alliierter Kontrolle

2.1.1 Regelwerk - Zum britischen Verständnis von

Jugendarbeit im Spiegel der

Erziehungskontrollanweisungen 98

2.1.2 Lernprozeß - Erwartungen an deutsche Jugendarbeit aus amerikanischer Sicht

2.1.3 Widerstände - Die Situation in der französischen Zone .... 115

2.1.4 Unterstützung und Behinderung - Sozialistische Jugend im Spannungsfeld der Besatzungspolitik

2.2 Rekonstruktionsphase - Sozialistische Jugend zwischen 1945 und 1946

2.2.1 Initiativen - Die Anfänge der sozialistischen Jugend- und Erziehungsarbeit von lokalen Gruppen zum überregionalen Netzwerk

Exkurs: Wurzeln - Grundzüge der Geschichte der

Kinderfreundebewegung und der SAJ vor 1933

2.2.2 AdressatInnen-Zielgruppen sozialistischer

Jugendarbeit

2.2.3. TrägerInnen-Personelle Ressourcen für

Leitungsaufgaben

2.2.4 Leitlinien - Zur Bedeutung der Pottensteiner Konferenz für die pädagogische Arbeit

2.3 Konsolidierungsphase - Sozialistische Jugend in den Jahren 1946 bis 1948

2.3.1 Ziviler Alltag - Konferenzen und Großveranstaltungen als Zeichen innerverbandlicher Stabilisierung 162

2.3.2 Zusammenarbeit - Der Beitrag der Sozialistischen

Jugend zu den Gesprächen in Haus Altenberg und dem Jugendhof Vlotho 
2.3.3 Akzeptanz - Zur wachsenden Einbindung der deutschen Sozialistischen Jugendbewegung in die Sozialistische Jugendinternationale

2.4 Differenzierungsphase - Sozialistische Jugend zwischen 1948 und 1951

2.4.1 Zäsur - Die Rolle der Sozialistischen Jugend in der institutionalisierten Jugendverbandsarbeit am Beispiel des Bundesjugendringes

2.4.2 Konsequenzen-Zur Dreiteilung der Arbeitsebenen auf der Heidelberger Konferenz

2.4.3 Gegensätze - Die Haltung des Verbandes zum Ost-West-Konflikt 187

2.5 Der Wert der kleinen Zahl - Zusammenfassende Betrachtungen über den Beitrag der sozialistischen Jugend- und Erziehungsarbeit zur politischen Bildung

Abschlußbemerkungen 196

Anhang und Literatur 198

A. Abkürzungsverzeichnis ..................................................... 198

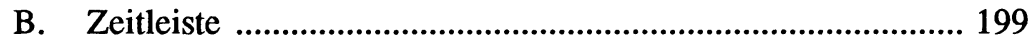

C. Materialien und Dokumente ............................................... 203

D. Personenverzeichnis ........................................................ 218

E. Quellen- und Literaturverzeichnis ..................................... 220 